\title{
Kennedy Graham
}

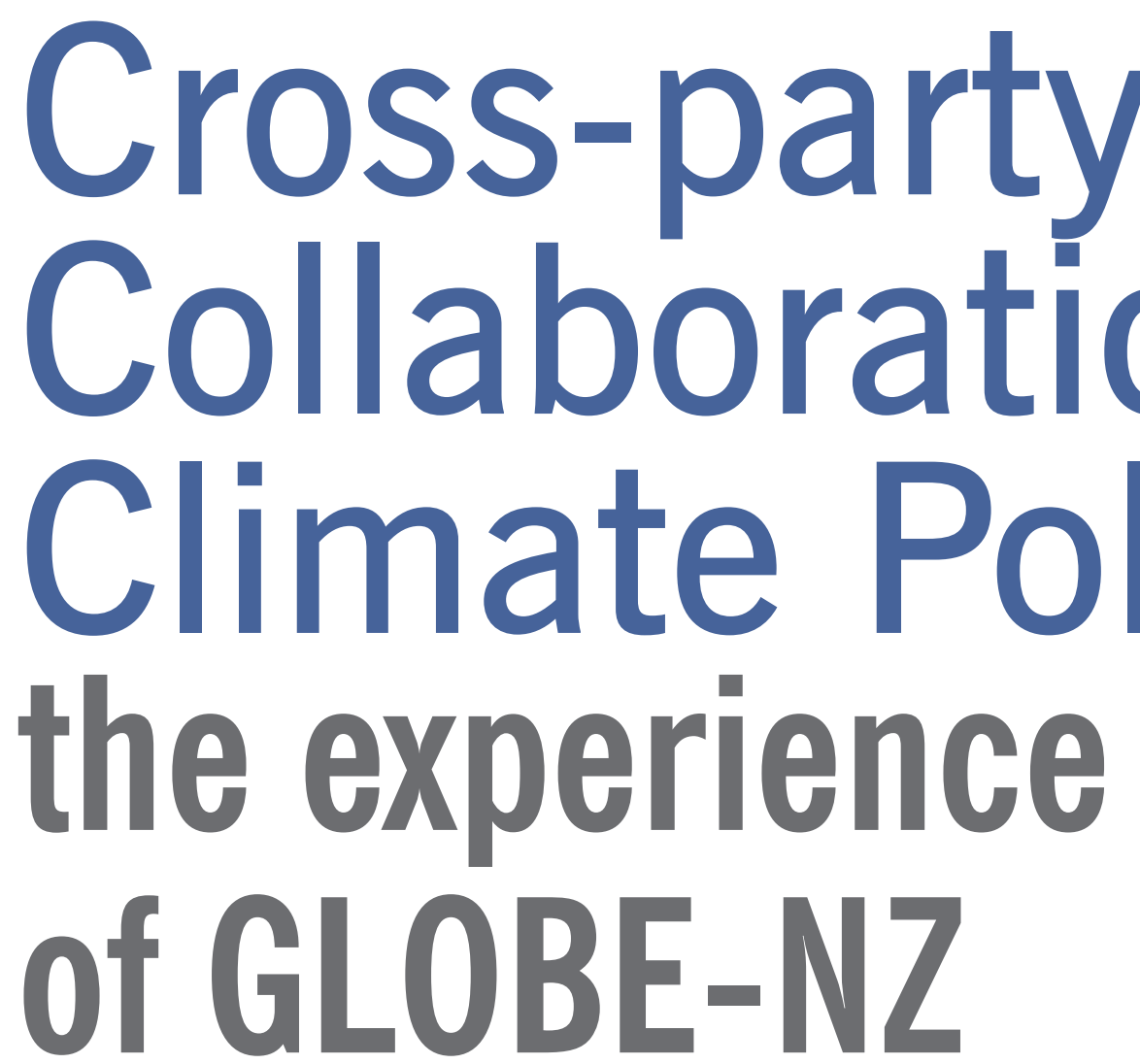

\section{Background}

Climate change has been described as the greatest challenge humanity has ever faced (Ban Ki-moon, 2014). No surprise, then, that it is challenging human problem solving, to an unprecedented degree. The 2015 Paris Agreement was a breakthrough in climate diplomacy, but progress is confined so far to the political psychology of achieving universality for emission reductions, a quarter of a century after the United Nations Framework Convention on Climate Change (1992) called for a return to baseline levels within a decade (article

4.2(a)). The 2015 agreement acknowledges that the Paris commitments are inadequate for a target of $2^{\circ} \mathrm{C}$, yet in 2016 emissions have begun to climb again.

There is a need for change in the political mindset at international and national levels. The former involves the world's diplomats; the latter involves its parliamentarians.

\section{GLOBE International}

GLOBE International was founded in 1989 as a non-profit entity under Belgian law by legislators from the United States (with senators Al Gore and John Kerry leading) plus the European Union, Japan and Russia. Its mission is to advance action by cross-party collaboration in legislation and budgetary oversight on sustainable development, with special emphasis on climate change, environmental accounting and governance, and forestry. GLOBE International believes members can, by working together, 'make more of a difference to unblocking political 
logjams at the multilateral level' and to 'holding governments to account for the implementation of international commitments' (GLOBE International, 2017).

GLOBE undertakes various activities: expert studies on national climate legislation, ${ }^{1}$ ministerial dialogues coinciding with G20 summits, and parliamentarian forums coinciding with UN conferences. ${ }^{2}$ Membership is open to parliamentarians from any country. Membership may be individual or MPs may establish national chapters. ${ }^{3}$ The secretariat is currently based in Mexico City, and the president of GLOBE International is Senator Alejandro Encinas Rodríguez.

\section{The Vivid report}

The expectation had always been that, if the New Zealand Parliament were to make progress towards anything approaching a broad policy consensus, we would need to go beyond briefings to a shared study of some kind. Having already met several times with the UK Committee on Climate Change, I sought their advice on consultants who might be equipped to undertake an expert study on domestic emission reductions in New Zealand. Several agencies were considered and, in December 2015, an exploratory meeting was held with Vivid Economics in London on the possibility of such an undertaking, following which a project proposal was developed.

\section{[The report] is also probably the most independent, in the sense of being undertaken by overseas experts and commissioned by a cross-party group, rather than by the government for the government.}

\section{GLOBE-NZ}

In mid-2015, with COP21 approaching, discussions got underway with GLOBE International on the idea of establishing a New Zealand chapter. ${ }^{4}$ Once national statutes were finalised I approached MP colleagues across the floor of the House, inviting them to sign up. Interest was strong and membership grew to $35 \mathrm{MPs}$ out of 121, from all seven parties. ${ }^{5}$ An executive committee of six MPs, one from each of six parties, was formed, with a chair and two vice-chairs.

Since late 2015, GLOBE-NZ has hosted briefings for its members from recognised experts: New Zealand climate ambassadors, climate scientists, economists, business chief executives, visiting political leaders and foreign legal experts. These briefings provided the 'glue' that began to bind a disparate group of New Zealand parliamentarians in seminar style, focusing on what is one of the most contentious subjects in New Zealand politics.
It became clear that philanthropic funding was needed, since the overall project costs would exceed the capacity of MPs to fund, even collectively.

A group of foundations, companies and individuals, spearheaded by Sir Stephen Tindall and his Tindall Foundation, agreed to cover project costs provided the study was genuinely crossparty. Three embassies agreed to cover travel costs. Ten MPs from six parties used portions of their office budgets to collectively cover the costs of a Wellingtonbased expert to facilitate the visits by the Vivid team to New Zealand. Altogether the project cost $\$ 240,700$, whose external funds I managed in a separate bank account as GLOBE-NZ chair. ${ }^{6}$

The terms of reference for Vivid were: to provide a consultancy paper for developing alternative, but equally effective, pathways for New Zealand's transformation toward a lowemission economy, consistent with the achievement of net-zero emissions of $\mathrm{CO}_{2}$ ('carbon neutrality') at a rate consistent with the global goal of limiting temperature rise to levels identified in the Paris Agreement.

The Vivid team was comprised of five experts, three of whom visited New Zealand (in August 2016, December 2016 and March 2017). The team met with several hundred people throughout New Zealand, including iwi representatives in Rotorua, and in Parliament met on each visit with the speaker, the climate minister and GLOBE-NZ members.

The Vivid report, Net Zero in New Zealand: scenarios to achieve domestic emissions neutrality in the second half of the century (Vivid Economics, 2017), was launched in the Beehive Theatrette at Parliament on 21 March 2017. Launches were also held by the Christchurch City Council on 22 March and the Auckland Council on 23 March.

The report has come to be recognised as one of the most comprehensive, thorough and influential studies undertaken on New Zealand climate policy. It is also probably the most independent, in the sense of being undertaken by overseas experts and commissioned by a cross-party group, rather than by the government for the government.

The report engages in 'scenario planning', a relatively new methodology designed to offer policymakers a choice of futures in response to a developing problem or crisis. The goal of zero net emissions for New Zealand at some time in the second half of the 21 st century responds to the commitment in the Paris Agreement for net zero global emissions within that period. Vivid sought to depict scenarios with that global obligation, shared by all 197 states parties, in mind.

The report identifies four scenarios, as follows:
Off-track: New Zealand largely focuses on exploiting low-cost emission- reduction opportunities, but does not significantly alter its land-use patterns.
- Innovative: New Zealand considerably reduces the emissions 
intensity of its economic activity through technological advances, accompanied by a structural shift away from pastoral agriculture to a more diverse range of land use, alongside extensive afforestation. Resourceful: New Zealand does not pursue extensive decarbonisation of the energy sector (because global progress is less rapid), but extensive afforestation is pursued.

- Net Zero in 2050: New Zealand combines the most ambitious aspects of the Innovative and Resourceful scenarios, sector by sector, and undertakes industry closure across the aluminium, oil refinery and iron and steel industries as required to reach net zero.

The report contains five conclusions:

1. Any pathway to reducing the country's domestic emissions will involve substantial change to patterns of energy supply and use, including moving towards a $100 \%$ renewables grid and substantial electrification of the passenger vehicle fleet and low-grade heat.

2. It is possible for New Zealand to move onto a pathway consistent with domestic net zero emissions in the second half of the century, but only if it alters its land-use patterns.

3. If New Zealand does seek to move its domestic economy onto a net-zeroconsistent trajectory, there is a choice between the extent to which it is able to make use of new technologies and the extent to which it needs to embark upon substantial afforestation.

4. If it chooses to substantially afforest and it is fortunate enough to benefit from the extensive availability of new technologies, it could be possible for the country to achieve domestic net zero emissions by 2050 .

5. Although afforestation will likely be an important element of any strategy to move to a net zero emissions trajectory in the period to 2050, alternative strategies will be needed after that.

There are nine recommendations; in short:
Policy

1. A trajectory for emissions price policy values should be factored into all government analyses, consistent with the Paris Agreement, implying higher values than currently in the emissions trading scheme.

2. Extension of a robust, predictable price to biological emissions would encourage land-use decisions to account for emissions intensity.

3. Emissions pricing should be accompanied by a range of changed market and regulatory arrangements, infrastructure deployment mechanisms, and specific support to address additional barriers and market failures.

4. Further investment in recommended
9. Improved understanding is needed of the distributional implications of differing low-emissions scenarios, and investigation of policy responses for alleviating any concerns.

\section{The parliamentary debates}

Such was the extent of public interest that Parliament convened a special debate on the report. The debate, on 13 April 2017, was perhaps a unique occasion; it is certainly rare for the House to suspend its normal legislative agenda to focus on a specific report. Subsequently, a series of informal debates on the report, involving MPs from most parties, was convened around the country by various organisations, in Blenheim, Dunedin, Christchurch and Hamilton.

\section{Following the debates, the executive committee turned its attention to "where to from here' ... it had always been recognised that, ... the hard part for cross-party dialogue would be focusing on short-term national policy issues.}

in the research and development of low-emissions technologies.

Institutions and principles

5. Political parties should reach common agreement in areas of climate policy in order to enhance coherence and predictability, while allowing room for an informed debate and party difference over policy design.

6. Independent institutions, backed by statute, can help assist Parliament and government in developing coherent national climate policy.

7. A holistic approach to policymaking, including economic and cultural interests, should be adopted, with meaningful consultation with iwi under the Treaty of Waitangi's principle of partnership.

8. There is an important need to upgrade the evidence base to support New Zealand low-emissions pathway planning.
Intimation of future policy progress was reflected in the April debate. MPs from every party spoke. New Zealand First and Māori Party MPs indicated 'personal views' that net zero by 2050 was a crucial goal for New Zealand. The Green co-leader James Shaw formally committed the party to that goal. Labour MPs called for stronger action by New Zealand to meet the goals of the Paris Agreement. The National MP on the GLOBE executive described 'this very fine Vivid report' as

an example of our Parliament working, I think, at its very best. That 35 members of this Parliament - representative of every party in this House - could come together to embark upon a project of common interest, of shared interest in climate change and climate change issues, is, I think, a historic and momentous event. 
The minister for climate change issues also commended the report: 'you cannot blame me for wanting to read it and take some bits out of it and think about how that kind of shapes the work that I am doing as a Minister'. All speakers acknowledged that a broad consensus was beginning to develop (Hansard, 2017).

\section{The Statement of Collaborative Purpose}

Following the debates, the executive committee turned its attention to 'where to from here'. It had always been recognised that, beyond receiving briefings and commissioning studies without advance commitment as to content, the hard part for cross-party dialogue would be focusing on short-term national policy issues. With the Vivid report in, and parliamentary
Zealand reaching 'net zero' domestic emissions as early in that period as possible;

2. Note the invitation to communicate to the UNFCCC, by 2020, a mid-century, long-term GHG emission strategy in accordance with the decision adopting the Paris Agreement (Paris, December 2015); ${ }^{9}$

3. Note, further to the call for long-term strategies, the 2050 Pathways Platform launched at COP22 (Marrakesh, November 2016), in which New Zealand is one of the 22 countries that 'have started or are about to start a process of preparing a 2050 pathway', ${ }^{10}$ recognising that six

\section{With the statement as its 'post-}

Vivid departure point', the executive considered what could be done, within the three months before the [2017] general election ...

debates concluding, the hard part was 'now'.

After several committee meetings, a Statement of Collaborative Purpose was agreed upon. This was new for the national chapter, being the first substantive occasion on which the group had spoken with one voice:

Members of GLOBE-NZ, in pursuit of the group's purposes as identified in Article 2 of its Statutes: ${ }^{7}$

1. Accept the formal commitment in the Paris Agreement (December 2015) to holding the increase in global average temperature to well below $2^{\circ} \mathrm{C}$ above pre-industrial levels and pursuing efforts to limit it to $1.5^{\circ} \mathrm{C}$, and the associated global goal of zero net emissions in the second half of the 21st century, with developed countries continuing to take the lead with economy-wide reduction targets, ${ }^{8}$ recognising that this means New
Parties have already communicated their national strategies; ${ }^{11}$

4. Welcome the report by Vivid Economics, commissioned by our group, entitled Net Zero in New Zealand: scenarios to achieve domestic emission neutrality in the second half of the century (March, 2017), which identifies four scenarios for emission reductions, two of which are consistent with the goal of $2^{\circ} \mathrm{C}$ and one of which may be consistent with the goal of $1.5^{\circ} \mathrm{C}$; and also the study underway by the Productivity Commission which will complement the work of the Vivid report;

5. Accept, as the basis for discussion as to their respective merits, the Innovative and Resourceful scenarios identified for New Zealand; and the Net Zero in 2050 scenario as a serious aspirational goal;
6. Plan to develop, through further expert advice, an indicative pathway (bounded by quantitative ranges) towards domestic emissions neutrality, having regard to the report's conclusions and recommendations, noting that the report applies 'scenario analysis across the New Zealand economy ... to help illuminate long-term low-emission pathways' (Executive Summary);

7. On the basis of such an indicative pathway and at an appropriate time, commence a dialogue within our group on policy measures, with an appropriate combination of market, regulatory and educational measures, to ensure a timely and just transition to a net zero or a low-carbon economy by 2050.

With the statement as its 'post-Vivid departure point', the executive considered what could be done, within the three months before the general election, to advance progress. Steps 1 through 4 were seen as relatively uncontentious. Step 5, however, represented forward movement in so far as all parties accepted Net Zero in 2050 as a 'serious aspirational goal'.

The two final steps - an indicative pathway towards emissions neutrality (step 6) and appropriate measures to that end (step 7) - represented the substantive challenge which GLOBE-NZ had been working towards. Accordingly, four MP members from three parties collaborated in commissioning two Wellington-based experts to produce reports on these subjects. These 'consultancy papers' were completed and circulated to GLOBE-NZ members in mid-September. Finally, acting in my capacity as outgoing chair, I circulated to all GLOBE-NZ members some personal thoughts about the progress of the group over the two-year period, and the potential challenges likely to confront the 'second-generation' group in the 52nd Parliament.

\section{The consultancy papers}

The two consultancy papers comprise a précis of where New Zealand climate policy thinking was at in late 2017. Nothing stands 
still; new policy formulation is already underway by the Labour-led government. But the two papers, both of exceptionally high quality, provide as good a torchlight into long-term planning, and short-term policy considerations, as anyone could hope for, including perhaps the executive branch.

\section{Towards a 2050 Pathway for New Zealand}

This paper (Young, 2017) breaks new ground. Taking the Vivid report's relevant scenarios as its departure point, it develops a 'broad-banded indicative pathway' to the end-goal. As noted in the paper, the scenarios were presented by Vivid as snapshots of the year 2050, but 'with the trajectory between now and then undefined' (p.8). The Young paper, in response to the terms of reference provided, develops a 'broad-banded indicative pathway that spans the three scenarios that place New Zealand on track to net zero emissions in the second half of the century' (p.10).

To that end, the paper uses the Resourceful and Net Zero in 2050 scenarios to define the boundaries of such a pathway (p.12). It analyses the sectoral (and subsectoral) pathways that would collectively produce the upper and lower bounds of the total national pathway. The figures, in summary, are shown in Table 1.

As depicted, the broad-banded pathway would commence from 56.7 MT (metric ton) net emissions in 2014 to reach a range in 2050 of $20.2 \mathrm{MT}$ (upper limit) to 1.8 MT (lower limit). The main sectoral reductions would be found in energy, from 32.1 MT to 9.4 MT (lower limit) and in agriculture, from 39.6 MT to 24.7 MT (lower limit). Forestry sequestration would increase from 24.2 MT in 2014 to 36.5 MT (lower limit).

If the lower range of $1.8 \mathrm{MT}$ is thereby achieved, this is effectively domestic emissions neutrality by 2050 . The pathway to the 2050 range of $20.2-1.8 \mathrm{MT}$ is a major step forward in national domestic climate policy planning. The sectoral and sub-sectoral paths through each year are depicted in graphs constructed by the author.

The other advance reflected in the paper is the extension of the pathway beyond the 2050 limit set by Vivid, out to 2070. This is critical because it illustrates that, not only is the heavy reliance on

Table 1: Emissions profiles in 1990, 2014 and 2050

\begin{tabular}{llrrrr}
\hline & & 1990 & 2014 & \multicolumn{2}{c}{2050} \\
\hline \multirow{2}{*}{ Energy } & & & & Resourceful & Net zero \\
& Electricity & 3.5 & 4.2 & 3.3 & 0.7 \\
& Transport & 8.8 & 14.1 & 5.8 & 3.9 \\
& Other fossil fuels & 10.2 & 11.9 & 8.3 & 3.0 \\
& Fugitives & 1.3 & 2.0 & 2.8 & 1.8 \\
Industry & Sub-total & 23.8 & 32.1 & 20.2 & 9.4 \\
Agriculture & & 3.6 & 5.2 & 4.2 & 1.4 \\
& Enteric fermentation & 26.3 & 28.6 & 18.7 & 14.3 \\
& Manure management & 0.7 & 1.3 & 1.0 & 0.9 \\
& Soils, liming, urea & 7.3 & 9.7 & 8.8 & 9.5 \\
& Other & 0 & 0 & 0 & 0 \\
Waste & Sub-total & 34.4 & 39.6 & 28.5 & 24.7 \\
Gross & & 4.1 & 4.1 & 3.8 & 2.7 \\
Forestry/LULUCF & & 65.8 & 81.1 & 56.6 & 38.3 \\
Net & & -28.9 & -24.2 & -36.4 & -36.5 \\
\hline
\end{tabular}

Figure 1. The Indicative Broad-banded Pathway to Net-zero Emissions by New Zealand

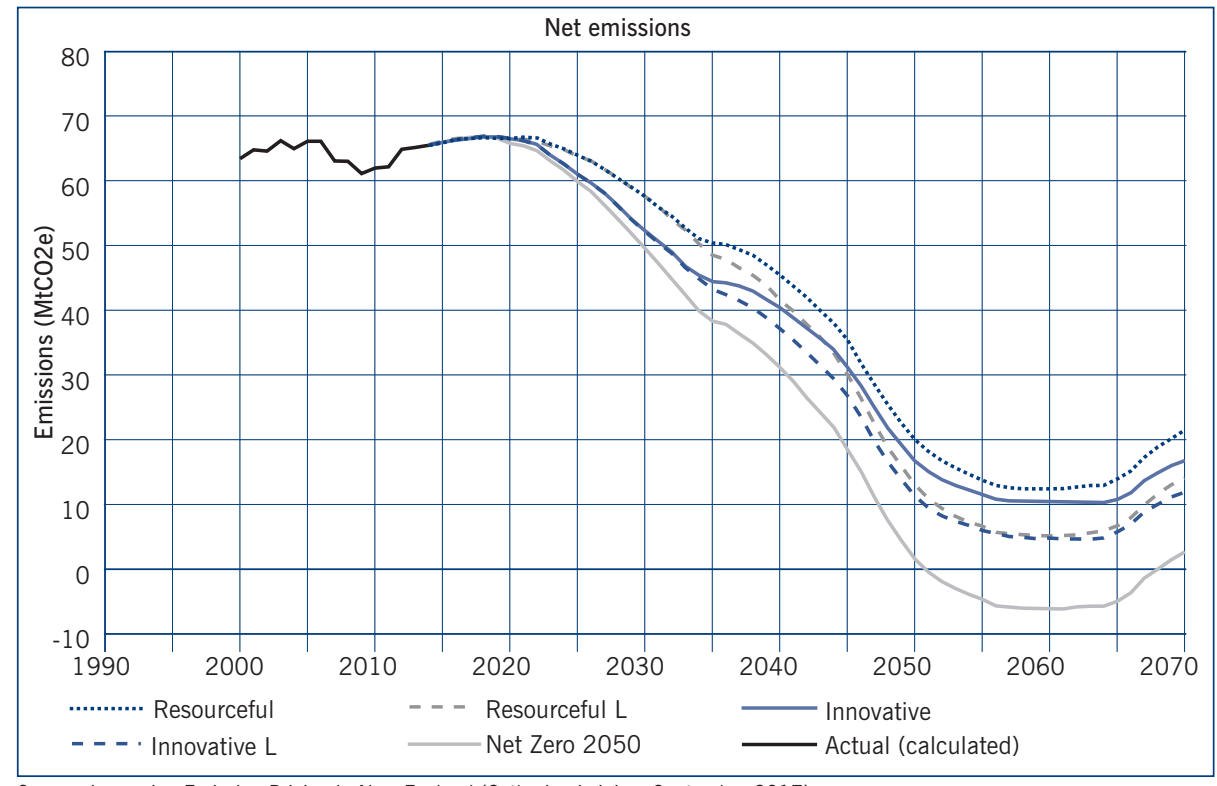

Source: Improving Emission Pricing in New Zealand (Catherine Leining, September 2017)

forestry sequestration in the first three decades essentially a credit card approach to neutrality, but even the lower limit (i.e. the most ambitious reduction pathway), which would effectively achieve neutrality by 2050 , will return to positive emissions around 2068. That is sobering news. This is depicted in Figure 1.

\section{Improving Emission Pricing in New Zealand} This paper (Leining, 2017) reviews the history, and weaknesses, of the emissions trading scheme (ETS), before providing a new assessment of what is feasible and effective in the short-term future. The paper considers the use of emissions trading and/or carbon taxes as instruments for achieving a 'robust and predictable emissions price' as called for in the Vivid report. It does not recommend the level of emission price ambition, which, in the author's view, is ultimately a political judgement.

Three options are considered: reforming unit supply and price settings in the current ETS; replacing the ETS with a carbon tax; and complementing the ETS with a carbon tax. The paper concludes 
that, if well-designed and based on good information and sound assumptions, an ETS or a carbon tax can deliver comparable outcomes. Both instruments would need to be positioned strategically within a broader and coordinated climate change policy portfolio to help deliver on national targets. A carbon tax is easier to understand than an ETS, but 'no less vulnerable to the winds of political change'. If a jurisdiction is starting from a blank slate, then either will do if it is done well and with commitment.

However, common perceptions that carbon taxes automatically offer more price ambition, more investment certainty, more revenue and better revenue recycling, more simplicity, more transparency and
7. enlist independent advice, for stronger foundation of public and cross-party support.

The two approaches outlined in these papers - identifying a banded pathway and reshaping the pricing mechanism consistent with such a pathway - are complementary. Together the papers provide an excellent, possibly an essential, route to parliamentary and governmental discourse on climate policy over the next critical few years.

\section{Conclusions from the 51st Parliament}

The lessons learnt from the '51st experience' are perhaps the following:

\section{GLOBE-NZ in the 51st Parliament had}

\section{a significant role, I believe, in helping the coalition government of the 52nd to formulate a long-term policy on climate change consistent with the objectives of Paris [Ageement].}

fewer business hand-outs 'do not hold true in theory or practice'. Changing instruments mid-course could result in the costs outweighing the anticipated gains.

In terms of ETS reform, the paper proposes a seven-step approach:

1. set an initial fixed five-year cap, and fix future caps for a full five years in advance;

2. add a price floor to be implemented as a reserve price at auction;

3. implement the price floor and price ceiling, using a unit reserve under the cap;

4. add indicative ten-year trajectories to the cap and price band, to guide future extensions;

5. require participants' use of international units to displace other supply under the cap;

6. introduce auctioning with a price band as soon as possible;

\section{Mutual respect}

In many sections of society the quality of mutual respect among protagonists is taken as a given. Not so in New Zealand politics, and especially not over climate change, which has witnessed some heated parliamentary exchanges. Out of chamber, however, it proves easier to develop mutual respect in informal settings, progressing from personal respect to a constructively critical regard for another party's positions. Without this, it's game over from the beginning.

\section{Information sharing}

The subtle, but in hindsight crucial, experience of the group was that we were assembling across parties, in however informal a manner, a shared dossier of information on the subject. Instead of entering the debating chamber with information and judgement from each party's expert armies to argue the case, we were beginning to use information in a common context. It makes a difference.

\section{Incremental progress}

Cross-party activity can be of various kinds. The weakest is a dialogue among parliamentarians who fundamentally disagree over certain issues. The next is a commissioning of studies, without commitment, to share in ownership of information. The strongest is collaboration to find a broader range of views that can form a consensus. GLOBE-NZ 51 began with the first of these in 2015 and finished with the third in 2017. In this respect progress was made.

\section{Backcasting}

With respect to climate change, the progression in international thinking in the recent COPs to look ahead to the long term (2050 and out to 2100) was mirrored in the work of the New Zealand chapter. The method of 'backcasting' - to find agreement through scenario methodology on a long-term goal (2050), proceeding back to 2030 and from there to 2020 - is proving more conducive to policy consensus. It's easier, of course, to agree on a long-term scenario, but if the proven methodology suggests that this is a precondition of a more insightful exchange for the short term, then so be it.

\section{Constitutional sensitivity}

The group's two-year experience produced some intriguing moments which challenged constitutional niceties. The first was the role of the minister and her relationship with a cross-party group of backbenchers, including from her own party. While nothing formally would preclude a minister from membership of a parliamentarian group, it would have been regarded as awkward and problematic. This has implications for the new government in the 52nd Parliament, whose climate minister was a leading member of the group in the 51st.

A second issue was the relationship between each MP on the GLOBE executive and his or her own caucus. On a few occasions, particularly as the group began to approach substantive policy issues (such as the Common Statement), each individual had to 'chance their arm' a bit before reporting back to their caucus. This 
is, however, the essence of true cross-party initiative. It put transparency and trust to the test, and executive members came through well enough.

\section{Challenges for the 52nd Parliament}

GLOBE-NZ in the 51st Parliament had a significant role, I believe, in helping the coalition government of the 52nd to formulate a long-term policy on climate change consistent with the objectives of Paris. It may also have gone some way to bridging an entrenched divide between the two major blocs in Parliament. The dynamics revealed some interesting, and to some surprising, moments, in which individuals were seen to be expressing reasoned views, with more political fluidity than would normally be found in the debating chamber.

Each parliamentary term is unique, as to both spread of membership and choice of government. The national chapter of GLOBE-NZ in the 52nd Parliament will be different from that in the 51st. Some 26 of the 35 MPs who were members in 2016-17 are returned to the new Parliament, but only two from the GLOBE executive are returned and both are ministers. So GLOBE 51 will need to reconstitute itself, not from scratch but as a new group. One issue is who should chair. There is an argument that the chair should always be an opposition member. This begs some nuanced matters of political judgement beyond scope here, but they will need to be addressed.
Can the experience of GLOBE 51 on climate change be emulated in other areas of pressing national policy: child poverty, housing, water quality, substance abuse? The New Zealand Parliament is not especially well developed on cross-party work compared with European counterparts. One instance exists on human rights to some good effect, and progress was achieved a few years ago in health through cooperative select committee work, but it is not the norm in the default adversarial nature of politics in Australia and New Zealand.

Some potential may exist in the areas cited above. But I believe it was a combination of long-term planning, together with a sense of moment and a need for policy predictability, that facilitated progress on climate change. The urgency felt around the world, post-Paris, plus a certain chemistry and dynamic particular to the group explained the progress made in this area at this particular stage. A positive attitude, from an appropriate distance, by the portfolio minister was another critical ingredient.

Time will tell whether something similar eventuates with other issues, and indeed whether further progress is made on climate in what is, in the 52nd Parliament, a fundamentally different setting.

\footnotetext{
1 The first edition of GLOBE's Climate Legislation Study was published in 2010, covering national legislation in 16 countries (including New Zealand); the fifth edition, covering 99 countries, was published in 2015.

2 These include parliamentarian summits coinciding with
}

the 1992 Rio Earth Summit and the 2005 G20 Ministerial Dialogue, and a series of biannual GLOBE legislator forums for cross-party policy dialogues. From 2008 the organisation established international policy commissions, specifically on 'climate and energy security' and 'land-use change and ecosystems'. The GLOBE Copenhagen Legislators Forum, coinciding with COP15 in 2009, adopted a set of forestry and terrestrial carbon position papers to support specific national legislative proposals in members' countries. In

2012, GLOBE convened the first world summit of legislators working on sustainable development and climate change, to coincide with the Rio+20 United Nations conference, producing the 'GLOBE Rio+20 Legislators' Protocol'. In

2013 the GLOBE Climate Legislation Initiative was launched at a parliamentarian summit in the UK, followed by a policy programme for environmental accounting at a second summit in Germany. In 2015, coinciding with COP21 in Paris, a GLOBE International Legislators' Summit on the impending Paris Agreement was convened in the French senate, and submitted a communiqué to the UN conference.

3 There are currently members from over 80 countries, with 40 national chapters established.

4 I had had a continuing relationship with GLOBE over the years, having visited Washington in 1989 from New York for discussions on climate issues with Senator Al Gore several times, and witnessing its establishment that year. In 1990 I convened an international parliamentarian workshop on climate change in Bellagio, Italy, involving the senator's advisers. As an MP I was part of the GLOBE delegation to the COPs in Copenhagen (2009), Doha (2012), Warsaw (2013) and Paris (2015), presenting for New Zealand in Paris, and also COP22 in Marrakech (2016). I had also participated in GLOBE's climate legislation study in 2010 and attended the GLOBE Legislators Summit at Rio +20 in 2012. It had been a long-standing promise on my part to set up a national chapter.

5 Membership in 2017 from parties was 11 National, 10 Green, 8 Labour, 3 New Zealand First, 1 Māori Party, 1 United Future, 1 ACT: see https://www.parliament.nz/en/ get-involved/features/mps-collaborate-across-party-lines-inresponse-to-climate-change/.

6 The GLOBE-NZ statutes preclude the group managing finances. As a result, I maintained a personal account for the non-MP project funds. The funds were duly declared in my annual MP statement of pecuniary interests, and on completion of the project the account was formally audited before being closed.

7 'Article 2. The promotion of global, regional and national policy processes for climate and environmental protection $\ldots ; 3$. The promotion of a cross-party discussion and cooperation on the environment, climate protection and nature conservation, as well as sustainable development.'

8 FCCC/CP/2015/10/Add 1 (Annex, Articles 2(1(a), 4(1 and 4)

9 FCCC/CP/2015/10/Add 1 (Decision 1/CP.21, para 35; and Annex, Article 4 (19).

10 http://newsroom.unfccc.int/unfccc-newsroom/high-levelclimate-champions-launch-2050-pathways-platform/.

11 http://unfccc.int/focus/long-term strategies/items/9971.php: Mexico, US, Canada, Germany, Benin, France.

\section{References}

Ban Ki-moon (2014), 'Opening remarks at 2014 Climate Summit', 23

September, https://www.un.org/sg/en/content/sg/

speeches/2014-09-23/opening-remarks-2014-climate-summit

GLOBE International (2017) 'The GLOBE legislators organisation (GLOBE)',

http://globelegislators.org/about-globe/25-globe-international

Hansard (2017) 'Special debate - GLOBE-NZ - report', New Zealand

Parliamentary Debates, 13 April, https:/www. parliament.nz/en/pb/

hansard-debates/rhr/combined/HansDeb_20170413_20170413_12

Leining, C. (2017) Improving Emission Pricing in New Zealand: a briefing

for GLOBE-NZ, Wellington: https://www.parliament.nz/media/4448/

improving-emission-pricing-in-nz-leining.pdf
Vivid Economics (2017) Net Zero in New Zealand: scenarios to achieve domestic emissions neutrality in the second half of the century (summary report and technical report), Wellington: http://www. vivideconomics.com/publications/net-zero-in-new-zealand; https:// www.parliament.nz/en/get-involved/features/mps-collaborate-acrossparty-lines-in-response-to-climate-change/

Young, P. (2017) Towards a 2050 Pathway for New Zealand: a discussion paper for GLOBE-NZ, Wellington: https://www. parliament.nz/ media/4449/towards-a-2050-pathway-for-new-zealand-young.pdf 